\title{
Deformation pattern and predictive value of right ventricular longitudinal strain in children with pulmonary arterial hypertension
}

\author{
Iolanda Muntean ${ }^{1}$, Theodora Benedek ${ }^{2}$, Mihaela Melinte ${ }^{3}$, Carmen Suteu $^{1,4^{*}}$ and Rodica Togãnel ${ }^{1}$
}

\begin{abstract}
Background: Right ventricular function has been identified as an important prognostic factor in children with pulmonary arterial hypertension. The aim of the study was to assess the deformation pattern and prognostic value of right ventricular longitudinal strain in children with pulmonary arterial hypertension.

Methods: We prospectively evaluated 46 children ( 25 with pulmonary arterial hyperetension and 21 age and sex matched controls) using conventional and speckle-tracking echocardiography, brain natriuretic peptide levels and clinical status expressed by WHO functional class and 6-min walking test. According to the clinical status after 12 months of follow-up, the pulmonary arterial hypertension patients were divided in two groups: non-worsening (13) and worsening (12).

Results: Right ventricular free wall longitudinal strain and strain rate were significantly lower in children with PAH compared with controls $(-24.72 \pm 3.48$ vs $-15.60 \pm 3.40, p=0.0001$ and $-1.44 \pm 0.09$ vs $-1.09 \pm 0.15, p=0.0001$, respectively). There was a more expressed decrease of basal than apical region of right ventricular free wall longitudinal strain/strain rate in pulmonary arterial hypertension patients compared with controls (strain: $p=0.0001$ vs $p=0.07$ and strain rate: $p=0.0001$ vs $p=0.002$ ). Comparing worsening and non-worsening pulmonary arterial hypertension patients there was a significant difference in Mid right ventricular free wall longitudinal strain $(-14.00 \pm 3.13$ vs. $-20.76 \pm 4.62$, $p=0.0001$ ). In multivariable logistic regression analysis Mid right ventricular free wall longitudinal strain was an independent predictor of worsening in pulmonary arterial hypertension children (OR 0.45; $95 \% \mathrm{Cl}: 0.21-0.96, p=0.041$ ). In ROC curve analysis a cut-off value of Mid right ventricular free wall longitudinal strain of $-18.50 \%$ predicted clinical worsening in pulmonary arterial hypertension children, with a sensitivity and specificity of 91.7 and $30.8 \%$, respectively (area under curve $=0.88 \pm 0.06,95 \% \mathrm{Cl}: 0.75-1.00, p=0.001$ ).
\end{abstract}

Conclusions: Two-dimensional speckle-tracking echocardiography is a complementary non-invasive tool for assessment of right ventricular function in children with severe pulmonary arterial hypertension, allowing also clinical prediction and segmental analysis of right ventricular myocardial performance in these patients.

Keywords: Right ventricle, Strain, Deformation pattern, Pulmonary arterial hypertension, Children

\footnotetext{
* Correspondence: suteucarmen@yahoo.com

${ }^{1}$ Clinic of Paediatric Cardiology, Institute of Cardiovascular Diseases and

Transplantation, University of Medicine and Pharmacy, Tîrgu-Mures, Romania

${ }^{4}$ Clinic of Paediatric Cardiology, Institute of Cardiovascular Diseases and

Transplantation, University of Medicine and Pharmacy Tîrgu-Mures, $50 \mathrm{Gh}$

Marinescu St, Tîrgu-Mures 540136, Romania

Full list of author information is available at the end of the article
} 


\section{Background}

Pulmonary arterial hypertension (PAH) is a rare disease in childhood that is related with significant morbidity and mortality. The most common types of $\mathrm{PAH}$ in pediatric population are PAH associated with congenital heart defects (chd-PAH) and idiopathic PAH (IPAH) [1-4], with a reported annual incidence rate of about 2.2 and 0.7 cases per million, respectively [5].

There are several clinical, laboratory and echocardiographic parameters that have been shown to be associated with higher risk of death in pediatric pulmonary hypertension, such as: Word Health Organization (WHO) functional class $3 / 4[1,4,6]$, elevated levels of brain natriuretic peptide (BNP) $[1,7,8]$ or evidence of right ventricular (RV) failure [1]. WHO functional class has been shown to correlate well with 6-min walk distance (6MWD) and hemodynamic parameters [1-3].

RV function has been identified as an important prognostic factor in patients with PAH regardless of the causal clinical entity $[9,10]$. Therefore, accurate evaluation of RV function is crucial in the management of these patients. This can be challenging because of RV anatomy. In clinical practice, a qualitative subjective evaluation of the RV systolic function is performed routinely. The conventional echocardiographic parameters such as right ventricular fractional area changes (RV-FAC), tricuspid annular plane systolic excursion (TAPSE), right ventricular myocardial performance index (RV-MPI), tricuspid annular systolic velocity (S') or RV systolic/diastolic (S/D) ratio have been validated until now in estimation of global RV performance in adults and in children as well [11-17]. The recently developed speckle-tracking based strain imaging has been reported in adult patients as a technique that allows a better quantitative assessment of regional myocardial motion and deformation in PAH patients [18, 19], however its usefulness in children has not been elucidated so far [14, 20, 21].

The aim of this study was to assess the deformation pattern and prognostic value of RV longitudinal strain in children with PAH.

\section{Methods}

\section{Study population and grouping}

This is a prospective clinical observational study. The study group consisted of forty six patients: twenty-five children with PAH and twenty-one age and sex matched healthy children as a control group (Table 1). All children underwent a complete physical examination, $6 \mathrm{~min}$ walking test, blood sampling for BNP serum level and complex echocardiographic examination.

PAH was defined as mean pulmonary arterial pressure $\geq 25 \mathrm{mmHg}$ at rest [1]. The PAH group consisted of children with idiopathic PAH $(n=5)$ or PAH associated with congenital heart defects, with tripartite right ventricle. The associated congenital heart defects in the study population were: ventricular septal defect $(n=12)$, complete atrioventricular septal defect $(n=5)$ and truncus arteriosus communis $(n=3)$, all with pulmonary hypertensive vascular disease (with right-to-left or bidirectional intracardiac shunting). All PAH patients in the present study were on pulmonary vasodilator medication in monotherapy or combined therapy (Table 1). Further we split the PAH patient group in nonworsening and worsening group depending on the clinical evolution and WHO functional class after a follow-up period of 12 months.

The control group consisted of children with no history of cardiovascular disease, normal electrocardiography and echocardiography recordings, who were investigated for chest pain or fatigability and in whom the presence of any heart disease was rulled out.

\section{Exclusion criteria}

Patients older than 18 years old, those with PAH secondary to left heart disease or single heart (Nice, 2013) [1] and patients with rhythm disturbances were excluded from the study.

\section{Echocardiographic image acquisition}

The children were scanned with iE33 (Philips Medical Systems, Best, Netherlands) ultrasound system using an S5-1 transducer, by a single sonographer. At least three consecutive beats were stored in cine-loop format. Frame rate (60 to 100 frames per second), depth and sector width were adjusted in order to obtain accurate speckle-tracking analysis of the RV myocardial deformation.

Conventional echocardiographic parameters such as RV-FAC, TAPSE, RV-MPI, S', RV S/D ratio, pulmonary ejection time (Tej), LV eccentricity index (LV-EI) and mean pulmonary arterial pressure (PAPm) were measured as recommended by current guidelines $[12,13,22-24]$.

\section{Two-dimensional speckle-tracking analysis}

Speckle-tracking analysis of the RV was performed offline, from the RV-focused 4-chamber view images, using commercially available software (QLAB 10, Philips Medical Systems, Best, Netherlands). The RV endocardial border has been automatically generated by the software and than manually adjusted if necesarry. A seven-segment model was created according to the software: three at the RV free wall, three at the interventricular septum (IVS) and one at the apex of the RV. Also, speckle-tracking RV longitudinal strain and strain rate curves were automatically generated for every segment (Fig. 1) [13, 17-20].

Longitudinal peak systolic strain (LpsS) and longitudinal peak systolic strain rate (LpsSR) were measured in the basal, midventricular and apical segments of the RV 
Table 1 Clinical and laboratory (BNP level) characteristics of normal controls and PAH patients

\begin{tabular}{|c|c|c|c|}
\hline Variable & Control $(n=21)$ & PAH patients $(n=25)$ & $P$ \\
\hline Age (y) & $10.97 \pm 3.48$ & $11.07 \pm 3.44$ & 0.821 \\
\hline Male (\%) & $10(47.61 \%)$ & $11(44.00 \%)$ & 1.000 \\
\hline $\mathrm{H}(\mathrm{cm})$ & $147.50(133.25,156.75)$ & $136(119.00,147.00)$ & 0.081 \\
\hline W (kg) & $42.15 \pm 18.15$ & $29.95 \pm 12.07$ & 0.010 \\
\hline BSA (m2) & $1.29 \pm 0.36$ & $1.05 \pm 0.27$ & 0.012 \\
\hline BMI $\left(\mathrm{m} / \mathrm{kg}^{2}\right)$ & $18.31 \pm 3.48$ & $15.53 \pm 2.97$ & 0.016 \\
\hline 6MWD (m) & $480.35 \pm 55.03$ & $413.66 \pm 75.31$ & 0.001 \\
\hline $\mathrm{SpO}_{2}$ before $6 \mathrm{MWT}(\%)$ & $98.00(95.20,98.90)$ & $85.71 \pm 9.52$ & 0.0001 \\
\hline $\mathrm{SpO}_{2}$ after $6 \mathrm{MWT}(\%)$ & $98.00(97.00,99.00)$ & $75.80 \pm 15.59$ & 0.0001 \\
\hline HR before 6MWT (bpm) & $86.15 \pm 11.79$ & $98.90 \pm 14.38$ & 0.190 \\
\hline HR after 6MWT (bpm) & $109.20 \pm 14.84$ & $114.90 \pm 16.09$ & 0.246 \\
\hline $\begin{array}{l}\text { WHO Functional class } \\
1 / 2 / 3 / 4\end{array}$ & NA & $\begin{array}{l}0 / 15 / 9 / 1 \\
0 / 60 \% / 36 \% / 4 \%\end{array}$ & \\
\hline BNP level (pg/ml) & $9.00(10.48,16.34)$ & $25.85(27.98,80.28)$ & 0.005 \\
\hline \multicolumn{4}{|l|}{ PAH type } \\
\hline Idiopathic & NA & $5(20 \%)$ & NA \\
\hline Ventricular septal defect & NA & $12(48 \%)$ & NA \\
\hline Atrioventricular septal defect & NA & $5(20 \%)$ & NA \\
\hline Truncus arteriosus communis & NA & $3(12 \%)$ & NA \\
\hline \multicolumn{4}{|l|}{ Medication no(\%) } \\
\hline Sildenafil & NA & $5(20 \%)$ & NA \\
\hline Bosentan & NA & $13(52 \%)$ & NA \\
\hline Combination (Sildenafil + Bosentan) & NA & $7(28 \%)$ & NA \\
\hline
\end{tabular}

Data are presented as means \pm SD or median (25th, 75 th percentiles) or as numbers (percentages)

$B M I$ body mass index, $B N P$ brain natriuretic peptide, $B S A$ body surface area, $H$ height, $H R$ heart rate, $P A H$ pulmonary arterial hypertension, $\mathrm{SpO}_{2}$ oxygen saturation, $W$ weight, 6MWD 6-min walk distance

a

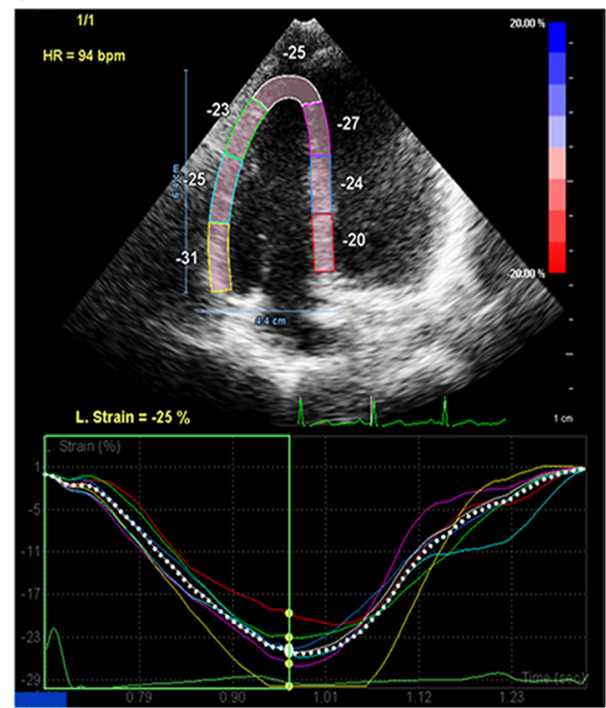

b

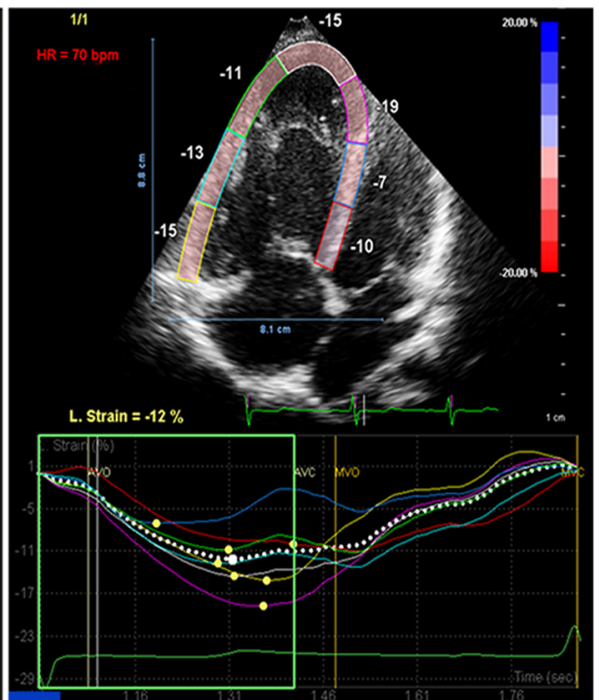

Fig. $12 \mathrm{D}$ speckle-tracking strain image of RV. LpsS in different segments. a control group; b PAH group. LpsS, longitudinal peak systolic strain; $\mathrm{PAH}$, pulmonary arterial hypertension; RV, right ventricle 
free wall, IVS and RV apex, respectivelly. RV free wall LpsS and LpsSR were calculated as the average of the three segments, and conventionally are presented as a negative value [13, 17-20].

\section{Six-minutes walking test (6MWT)}

$6 \mathrm{MWT}$ was done corresponding to the American Thoracic Society for adults [25]. Children were instructed to walk as fast as possible on a flat ground for $6 \mathrm{~min}$. Before and after the test, heart rate and transcutaneaus oxygen saturation $\left(\mathrm{SpO}_{2}\right)$ were measured by pulse oximeter. 19 controls and $23 \mathrm{PAH}$ patients were able to perform 6MWT.

\section{Functional class}

The functional class was established according to WHO class system [26].

\section{Measurement of BNP}

All blood samples were taken on the day of echocardiographic examination. The samples were centrifugated, and plasma was stored at $-70{ }^{\circ} \mathrm{C}$ until analysis was performed. BNP was assayed on an automatic immunoassay analyzer (Architect i1000SR, Abbott Diagnostics).

\section{Follow-up}

All PAH children were evaluated after 12 months for the occurence of the primary end point, clinical worsening. Clinical worsening was defined as increase in WHO functional class.

\section{Statistical analysis}

Statistical analysis was performed using SPSS version 20 (IBM SPSS STATISTICS 20). Data were labelled as nominal or quantitative variables. Nominal variables were expressed as numbers or percentages. Quantitative variables were tested for normality of distribution using Kolmogorov-Smirnov test and were expressed by mean \pm standard deviation or median and percentiles $(25 ; 75 \%)$, whenever appropriate. Differences between the mean or median between two groups were analysed using the t-test, Mann-Whitney test or chi-test when appropriate. Differences between three groups with normally distributed variables were analysed using ANOVA test with Bonferroni posthoc processing. Multivariate analysis was carried out using logistic regressions. We use as dependent variable the groups of PAH children (worsening and non-worsening). The covariates were Mid RV free wall LpsS, Mid RV free wall LpsSR, Apical RV free wall LpsS, BNP and LV EI. Receiver-operating characteristic curves were constructed, and areas under curve were calculated. Sensitivities and specificities were determined for the ability to identify worsening PAH children. Intraobserver reliability was assessed after reexamination by the same examiner 2 weeks after the initial examination, by intraclass correlation coefficient. A $p$-value of $<0.05$ was considered statistically significant.

\section{Results \\ Clinical and laboratory characteristics}

Twenty-five consecutive children with PAH and twentyone age and sex matched normal children were studied. The main clinical characteristics of the study groups are presented in Table 1. Children with PAH had lower body weight, body surface area and body mass index, probably explained by the impact of disease on nutritional status of PAH patients. The 6MWD, mean $\mathrm{SpO} 2$ before and after 6MWT were significantly lower in patients with PAH compared with controls. More than half of the $\mathrm{PAH}$ children were in WHO functional class 2. Plasma BNP level was significantly higher in patients with $\mathrm{PAH}$ compared with controls.

\section{Conventional echocardiographic data}

The conventional echocardiographic parameters of the two groups are compared in Table 2. RV-MPI, RV S/D ratio, indexed RA area, LV EI were significantly higher and RV-FAC, TAPSE, Tej and S' were significantly lower in PAH group than in control group, indicating RV function impairment in patients with PAH. There was no

Table 2 Comparison of conventional echocardiographic parameters between normal controls and PAH patients

\begin{tabular}{llll}
\hline Variable & Control $(n=21)$ & PAH $(n=25)$ & $P$ \\
\hline PAPm $(\mathrm{mmHg})$ & NA & $62.83 \pm 17.42$ & NA \\
TR $(\mathrm{mmHg})$ & $\mathrm{NA}$ & $93.76 \pm 24.52$ & $\mathrm{NA}$ \\
sRV pressure $(\mathrm{mmHg})$ & $\mathrm{NA}$ & $104.80 \pm 30.82$ & $\mathrm{NA}$ \\
Pericardial effusion & $\mathrm{NA}$ & $7 / 25(28 \%)$ & $\mathrm{NA}$ \\
RV-FAC (\%) & $45.36 \pm 5.60$ & $37.24 \pm 13.12$ & 0.008 \\
Indexed RV end-diastolic & $9.82(9.23,12.05)$ & $15.88 \pm 5.07$ & 0.0001 \\
area ( $\left.\mathrm{cm}^{2}\right)$ & & & \\
Indexed RV end-systolic & $5.79 \pm 1.18$ & $10.22 \pm 4.69$ & 0.0001 \\
area (cm $\left.{ }^{2}\right)$ & & & \\
RV MPI & $0.12 \pm 0.07$ & $0.32(0.24,0.51)$ & 0.0001 \\
TAPSE (cm) & $2.19 \pm 0.47$ & $1.79 \pm 0.60$ & 0.019 \\
RV S/D ratio & $0.82(0.81,1.03)$ & $1.30 \pm 0.33$ & 0.0001 \\
Indexed RA area $\left(\mathrm{cm}^{2}\right)$ & $8.41 \pm 1.32$ & $11.87(9.53,14,57)$ & 0.0001 \\
Tej (ms) & $319.01 \pm 33.45$ & $273.05 \pm 31.04$ & 0.0001 \\
LV-EI & $1.02(0.97,1.04)$ & $1.33(1.21,1.56)$ & 0.0001 \\
S' $^{\prime}(\mathrm{cm} / \mathrm{s})$ & $13.62 \pm 1.78$ & $11.75 \pm 3.53$ & 0.026 \\
LV-EF & $69.00 \pm 4.71$ & $71.20 \pm 9.88$ & 0.330 \\
\hline
\end{tabular}

Data are presented as means \pm SD or median (25th, 75th percentiles) $F A C$ fractional area change, $L V$-EF left ventricular ejection fraction, $L V$ - $E l$ left ventricular eccentricity index, MPI myocardial performance index, $P A H$ pulmonary arterial hypertension, $P A P m$ mean pulmonary arterial pressure, $R A$ right atrium, $R V$ right ventricle, $S^{\prime}$ tricuspid annular systolic velocity, $S / D$ ratio systolic/diastolic ratio, $s R V$ pressure systolic right ventricular pressure, TAPSE tricuspid annular plane systolic excursion, Tej pulmonary ejection time, $T R$ tricuspid regurgitation 
difference between the groups regarding left ventricular ejection fraction (LV-EF).

\section{Two-dimensional speckle-tracking echocardiography} Table 3 shows the speckle-tracking parameters of control group and PAH patients. $R V$ free wall LpsS and LpsSR were significantly lower in PAH patients than in controls (Fig. 2a and b). RV free wall LpsS and LpsSR were higher in basal segment $(-28.19 \pm 5.47$ and $-1.61 \pm$ $0.19)$ in comparison with the apical segment $(-20.00 \pm$ 7.58 and $-1.21 \pm 0.18)$ in healthy children, sugesting a base-to-apex gradient. This base-to-apex gradient was not observed in PAH children (Fig. 3a and b). However, in PAH patients there was a more expressed decrease of LpsS and LpsSR in the basal region of the RV free wall compared with the apical one (Fig. 3a and b). Because of lack of the basal septal region in most of chd-PAH patients, LpsS and LpsSR could not be accurately measured in this segment.

Table 3 Comparison of longitudinal strain indices in different RV segments between control group and PAH children

\begin{tabular}{|c|c|c|c|}
\hline Variable & $\begin{array}{l}\text { Control group } \\
(n=21)\end{array}$ & PAH children $(n=25)$ & $p$ \\
\hline \multicolumn{4}{|l|}{$R V-L p s S(\%)$} \\
\hline RV free wall & $-24.72 \pm 3.48$ & $-15.60 \pm 3.40$ & 0.0001 \\
\hline $\begin{array}{l}\text { Basal RV free } \\
\text { wall }\end{array}$ & $-28.19 \pm 5.47$ & $-12.80 \pm 4.26$ & 0.0001 \\
\hline Mid RV free wall & $-26.00 \pm 4.45$ & $-17.52 \pm 5.20$ & 0.0001 \\
\hline $\begin{array}{l}\text { Apical RV free } \\
\text { wall }\end{array}$ & $-20.00 \pm 7.58$ & $-16.48 \pm 4.96$ & 0.077 \\
\hline Apex & $-23.66 \pm 5.95$ & $-17.76 \pm 4.47$ & 0.0001 \\
\hline \multicolumn{4}{|l|}{ IVS } \\
\hline Apical IVS & $-27.33 \pm 5.59$ & $-19.00(-20.50,-16.00)$ & 0.0001 \\
\hline Mid IVS & $-24.38 \pm 5.34$ & $-17.36 \pm 5.70$ & 0.0001 \\
\hline Basal IVS & $-17.00 \pm 4.18$ & NA & NA \\
\hline \multicolumn{4}{|l|}{$R V-\operatorname{Lps} S R\left(s^{-1}\right)$} \\
\hline RV free wall & $-1.44 \pm 0.09$ & $-1.09 \pm 0.15$ & 0.0001 \\
\hline $\begin{array}{l}\text { Basal RV free } \\
\text { wall }\end{array}$ & $-1.61 \pm 0.19$ & $-1.00 \pm 0.15$ & 0.0001 \\
\hline $\begin{array}{l}\text { Mid RV free } \\
\text { wall }\end{array}$ & $-1.50 \pm 0.17$ & $-1.23 \pm 0.31$ & 0.001 \\
\hline $\begin{array}{l}\text { Apical RV free } \\
\text { wall }\end{array}$ & $-1.21 \pm 0.18$ & $-1.04 \pm 0.16$ & 0.002 \\
\hline Apex & $-1.28 \pm 0.26$ & $-1.09 \pm 0.19$ & 0.009 \\
\hline \multicolumn{4}{|l|}{ IVS } \\
\hline Apical IVS & $-1.30(-1.60,-1.22)$ & $-1.21 \pm 0.26$ & 0.016 \\
\hline Mid IVS & $-1.45 \pm 0.32$ & $-1.11 \pm 0.30$ & 0.001 \\
\hline Basal IVS & $-1.14 \pm 0.24$ & NA & NA \\
\hline
\end{tabular}

Data are presented as means \pm SD or median (25th, 75th percentiles) c control, IVS interventricular septum, LpsS longitudinal peak systolic strain, LPSSR longitudinal peak systolic strain rate, NA no available, $P A H$ pulmonary arterial hypertension, $R V$ right ventricle
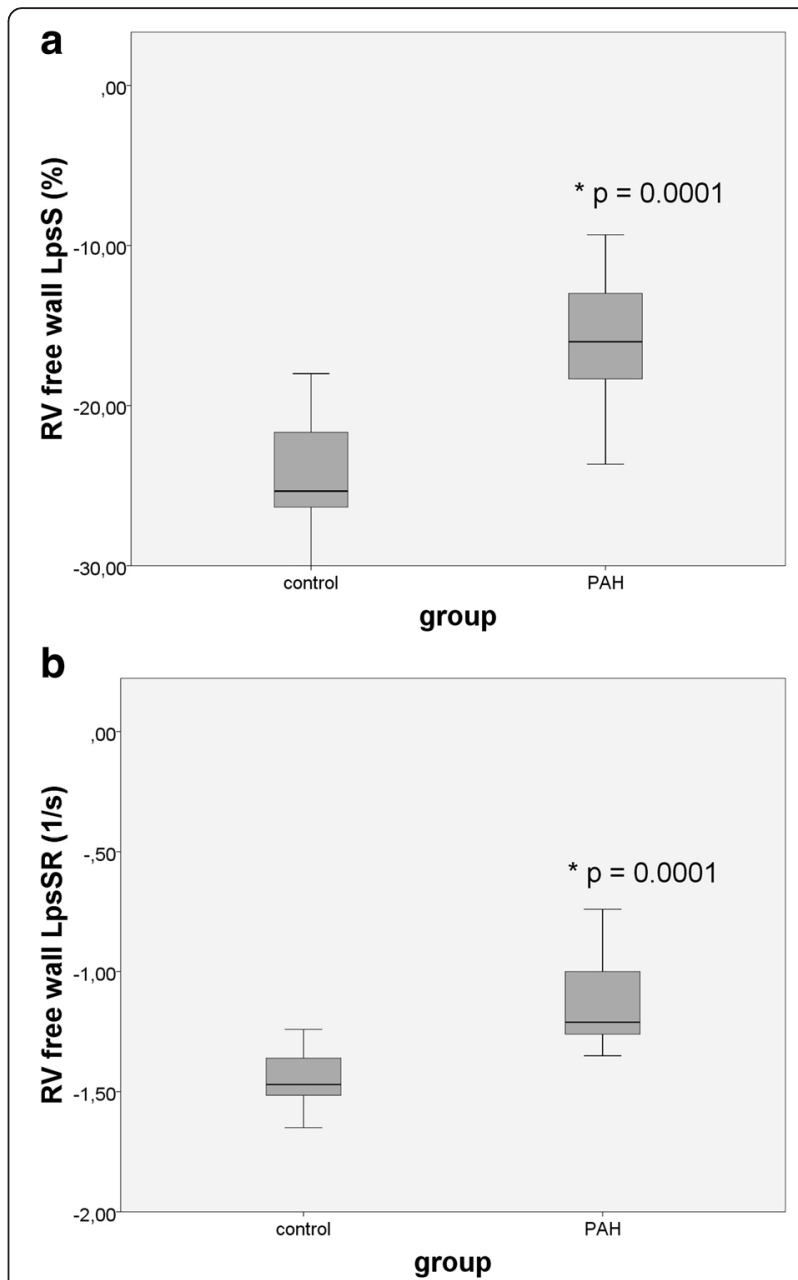

Fig. 2 Comparison between controls and PAH patients regarding 2D strain indices of RV free wall; $\mathbf{a}$ LpsS $\mathbf{b}$ LpsSR. c, control; LpsS, longitudinal peak systolic strain; LpsSR, longitudinal peak systolic strain rate; $\mathrm{PAH}$, pulmonary arterial hypertension; $\mathrm{RV}$, right ventricle; ${ }^{*} p<0.05$

\section{Predictive value of strain imaging}

After 12 months of follow-up, twelve children with PAH $(48 \%)$ presented clinical worsening with augmentation of the WHO functional class.

Table 4 show comparison of clinical, BNP level, conventional echocardiographic parameters, and longitudinal strain values (LpsS and LpsSR) in different RV segments in two PAH groups: non-worsening and worsening. Although, all parameters are impaired in worsening group compared with non-worsening group, there is significant difference only in case of BNP level, LV-EI, Mid RV free wall LpsS, Apical RV free wall LpsS, Mid RV free wall LpsSR.

Figure 4 show comparison of longitudinal strain values (LpsS and LpsSR) in different RV segments in three study groups: non-worsening PAH children, worsening PAH children and controls. All, but the apical RV free 

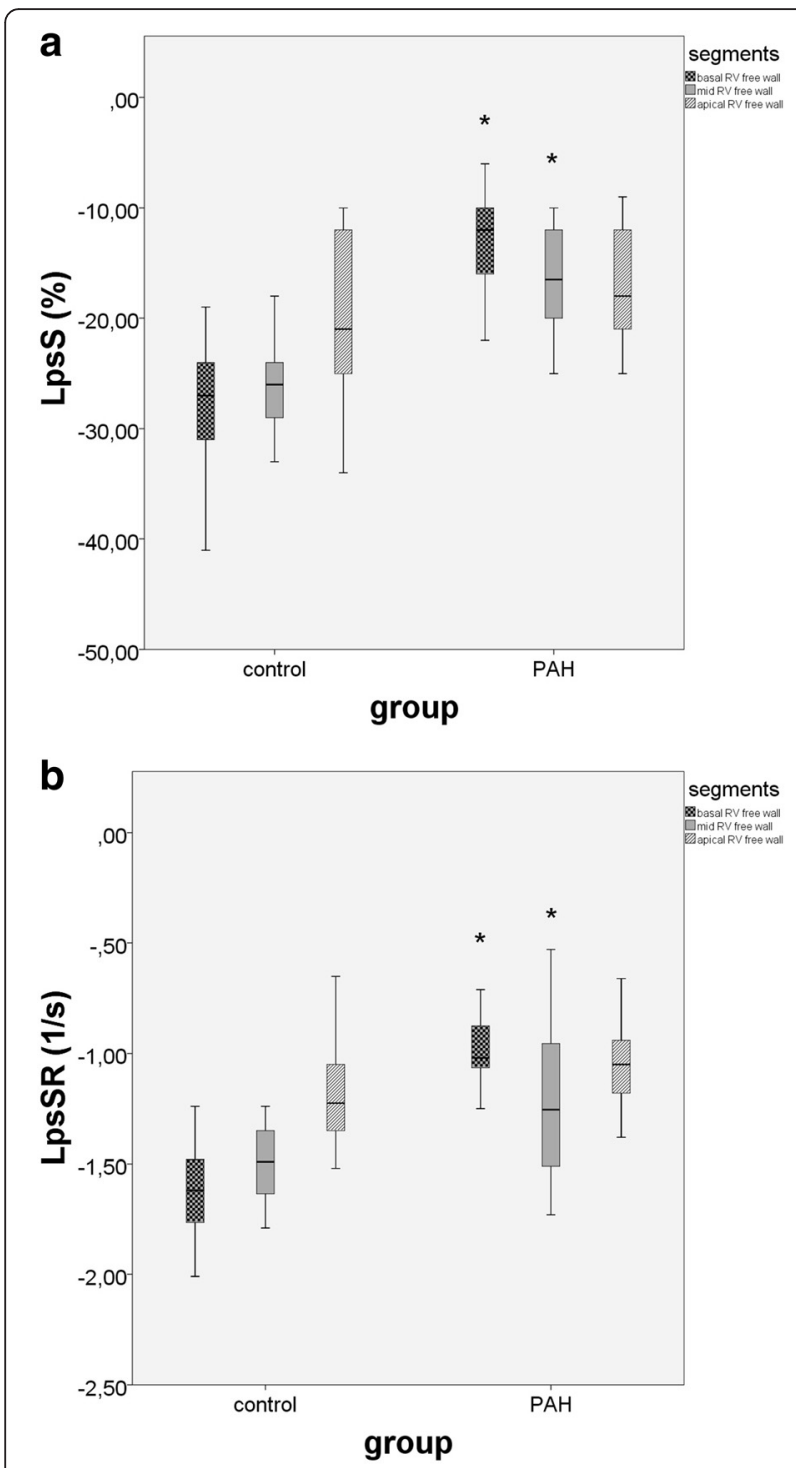

Fig. 3 Comparison between control group and PAH patients regarding 2D strain measurements of RV free wall segments: basal, mid and apical. a LpsS; b LpsSR. LpsS, longitudinal peak systolic strain; LpsSR, longitudinal peak systolic strain rate; $\mathrm{PAH}$, pulmonary arterial hypertension; RV, right ventricle; * PAH vs control group, $p<0.05$

wall LpsS were significantly lower in non-worsening PAH children compared with controls (Fig. 4). On the other hand, all RV free wall segments LpsS decreased significantly in worsening PAH children compared with controls. Comparing worsening and non-worsening PAH groups, only Mid and Apical RV free wall LpsS decreased significantly. Longitudinal strain rate was significantly lower in Basal RV free wall segment among nonworsening PAH children compared with normal controls. Only Mid RV free wall LpsSR decreased significantly among worsening compared with non-worsening PAH children.
We performed a multivariable logistic regression analysis, considering the worsening versus non-worsening $\mathrm{PAH}$ children as dependent variables and the BNP, LVEI, Mid RV free wall LpsS, Apical RV free wall LpsS and Mid RV free wall LpsSR, as covariates. After controlling for these covariates, multivariate analysis showed that Mid RV free wall LpsS was an independent predictor of worsening in PAH children (Table 5).

In ROC curve analysis, a cut-off value of Mid RV free wall LpsS of $-18.50 \%$ predicted clinical worsening in PAH children, with a sensitivity and specificity of 91.7 and $30.8 \%$, respectively. (area under curve $=0.88 \pm 0.06$, 95 \% CI: 0.75-1.00, $p=0.001$, Fig. 5.)

\section{Intraobserver reliability}

Intraobserver reliability assessed by intraclass correlation coefficient was 0.90 ; $95 \%$ CI (0.76-9.96), $p=0.0001$.

\section{Discussion}

$\mathrm{RV}$ function is an important prognostic factor in $\mathrm{PAH}$ [1], however its echocardiographic assessment is challenging in adults and in children as well, due to the particular anatomy of the RV $[13,14,17,19,20,22]$. Although, conventional echocardiographic parameters are largely used in clinical practice even in children, they have some intrinsic limitations [13-17]. These indices miss information regarding regional variation in function.

The present study has some important findings: 1) children with PAH seem to have a deterioration pattern of regional longitudinal deformation of RV: there is an initial decrease of strain/strain rate in the basal region followed by the mid/apical region 2) Mid RV free wall LpsS has predictive value in PAH children.

\section{RV strain in children}

Two-dimensional (2D) speckle-tracking echocardiography has been recently introduced for assessment of myocardial performance. Several previous reports have shown its accuracy and feasibility to assess RV function in adults $[18,19,27]$. Only a few study have used this technique to measure regional RV deformation in $\mathrm{PAH}$ children $[14,17,20,21]$. In this study, we evaluated RV longitudinal deformation pattern in PAH children compared with normal controls.

We found an average value of $-24.72 \pm 3.48$ for $\mathrm{RV}$ free wall LpsS and $-1.51 \pm 0.23$ for LpsSR in normal children, comparable with those reported in the literature $[28,29]$. The slightly different values between studies could be explained by the use of different equipment and software [30]. Also, we found a base-to-apex gradient of RV segmental longitudinal strain indices in normal controls. Levy et al. reported this pattern in healthy adults and children as well [29]. 
Table 4 Comparison of clinical, BNP level, conventional echocardiographic parameters, and longitudinal strain values (LpsS and LpsSR) in different RV segments in two PAH groups: non-worsening and worsening

\begin{tabular}{|c|c|c|c|}
\hline Variable & $\begin{array}{l}\text { Non-worsening } \\
\text { PAH children }(n=13)\end{array}$ & $\begin{array}{l}\text { Worsening } \\
\text { PAH children }(n=12)\end{array}$ & $p$ \\
\hline $6 \mathrm{MWD}(\mathrm{m})$ & $416.41 \pm 68.72$ & $380.90 \pm 104.00$ & 0.341 \\
\hline SpO2 before 6MWT (\%) & $86.00 \pm 11.11$ & $84.30 \pm 7.83$ & 0.689 \\
\hline SpO2 after 6MWT (\%) & $77.41 \pm 18.22$ & $74.50 \pm 11.53$ & 0.667 \\
\hline WHO Functional class & $2.38 \pm 0.50$ & $2.50 \pm 0.67$ & 0.631 \\
\hline $\mathrm{BNP}_{0}$ level $(\mathrm{pg} / \mathrm{ml})$ & $30.53 \pm 37.03$ & $82.01 \pm 74.80$ & 0.039 \\
\hline PAPm $(\mathrm{mmHg})$ & $61.53 \pm 18.25$ & $64.36 \pm 17.13$ & 0.701 \\
\hline $\mathrm{TR}(\mathrm{mmHg})$ & $91.23 \pm 31.74$ & $96.50 \pm 14.05$ & 0.602 \\
\hline sRV pressure $(\mathrm{mmHg})$ & $98.61 \pm 40.41$ & $111.50 \pm 14.05$ & 0.297 \\
\hline Pericardial effusion & 2/13 (8 \%) & $5 / 12(20 \%)$ & 0.200 \\
\hline RV-FAC (\%) & $41.07 \pm 15.10$ & $33.08 \pm 9.51$ & 0.131 \\
\hline RV MPI & $0.26(0.24,0.39)$ & $0.35(0.29,0.59)$ & 0.129 \\
\hline TAPSE (cm) & $1.93 \pm 0.59$ & $1.64 \pm 0.61$ & 0.247 \\
\hline RV S/D ratio & $1.24 \pm 0.28$ & $1.36 \pm 0.39$ & 0.367 \\
\hline Indexed RA area $\left(\mathrm{cm}^{2}\right)$ & $12.63 \pm 3.33$ & $15.35 \pm 15.70$ & 0.547 \\
\hline Tej (ms) & $280.50 \pm 31.95$ & $264.98 \pm 29.18$ & 0.219 \\
\hline LV-El & $1.31 \pm 0.17$ & $1.56 \pm 0.26$ & 0.010 \\
\hline $\mathrm{S}^{\prime}(\mathrm{cm} / \mathrm{s})$ & $12.83 \pm 3.34$ & $10.58 \pm 3.50$ & 0.114 \\
\hline LV-EF & $71.76 \pm 11.07$ & $70.58 \pm 8.86$ & 0.771 \\
\hline \multicolumn{4}{|l|}{$R V-L p s S(\%)$} \\
\hline RV free wall & $-17.38 \pm 2.51$ & $-13.66 \pm 3.24$ & 0.004 \\
\hline Basal RV free wall & $-12.69 \pm 4.64$ & $-12.91 \pm 4.01$ & 0.899 \\
\hline Mid RV free wall & $-20.76 \pm 4.62$ & $-14.00 \pm 3.13$ & 0.0001 \\
\hline Apical RV free wall & $-18.69 \pm 4.00$ & $-14.08 \pm 4.92$ & 0.017 \\
\hline Apex & $-19.15 \pm 4.25$ & $-16.25 \pm 4.37$ & 0.106 \\
\hline \multicolumn{4}{|l|}{ IVS } \\
\hline Apical IVS & $-19.69 \pm 5.49$ & $-19.00(-22.00,-13.00)$ & 0.337 \\
\hline Mid IVS & $-18.30 \pm 4.76$ & $-16.33 \pm 6.63$ & 0.399 \\
\hline Basal IVS & NA & NA & NA \\
\hline \multicolumn{4}{|l|}{$R V-\operatorname{Lps} S R\left(s^{-1}\right)$} \\
\hline RV free wall & $-1.16 \pm 0.12$ & $-1.01 \pm 0.13$ & 0.008 \\
\hline Basal RV free wall & $-1.00 \pm 0.19$ & $-1.00 \pm 0.09$ & 0.956 \\
\hline Mid RV free wall & $-1.37 \pm 0.27$ & $-1.07 \pm 0.29$ & 0.013 \\
\hline Apical RV free wall & $-1.11 \pm 0.12$ & $-0.97 \pm 0.16$ & 0.090 \\
\hline Apex & $-1.15 \pm 0.19$ & $-1.04 \pm 0.18$ & 0.166 \\
\hline \multicolumn{4}{|l|}{ IVS } \\
\hline Apical IVS & $-1.21 \pm 0.32$ & $-1.20 \pm 0.20$ & 0.896 \\
\hline Mid IVS & $-1.17 \pm 0.27$ & $-1.05 \pm 0.34$ & 0.372 \\
\hline Basal IVS & NA & NA & NA \\
\hline
\end{tabular}

Data are presented as means \pm SD or median (25th, 75th percentiles) or as numbers (percentages)

$B N P$ brain natriuretic peptide, FAC fractional area change, IVS interventricular septum, LpsS longitudinal peak systolic strain, $L p s S R$ longitudinal peak systolic strain rate, $L V$-EF left ventricular ejection fraction, $L V$-EI left ventricular eccentricity index, MPI myocardial performance index, $N A$ no available, $P A H$ pulmonary arterial hypertension, $P A P m$ mean pulmonary arterial pressure, $R A$ right atrium, $R V$ right ventricle, $S^{\prime}$ tricuspid annular systolic velocity, $S / D$ ratio systolic/diastolic ratio, $\mathrm{SpO}_{2}$ oxygen saturation, $s R V$ pressure systolic right ventricular pressure, TAPSE tricuspid annular plane systolic excursion, Tej pulmonary ejection time, $T R$ tricuspid regurgitation, 6MWD 6-min walk distance 


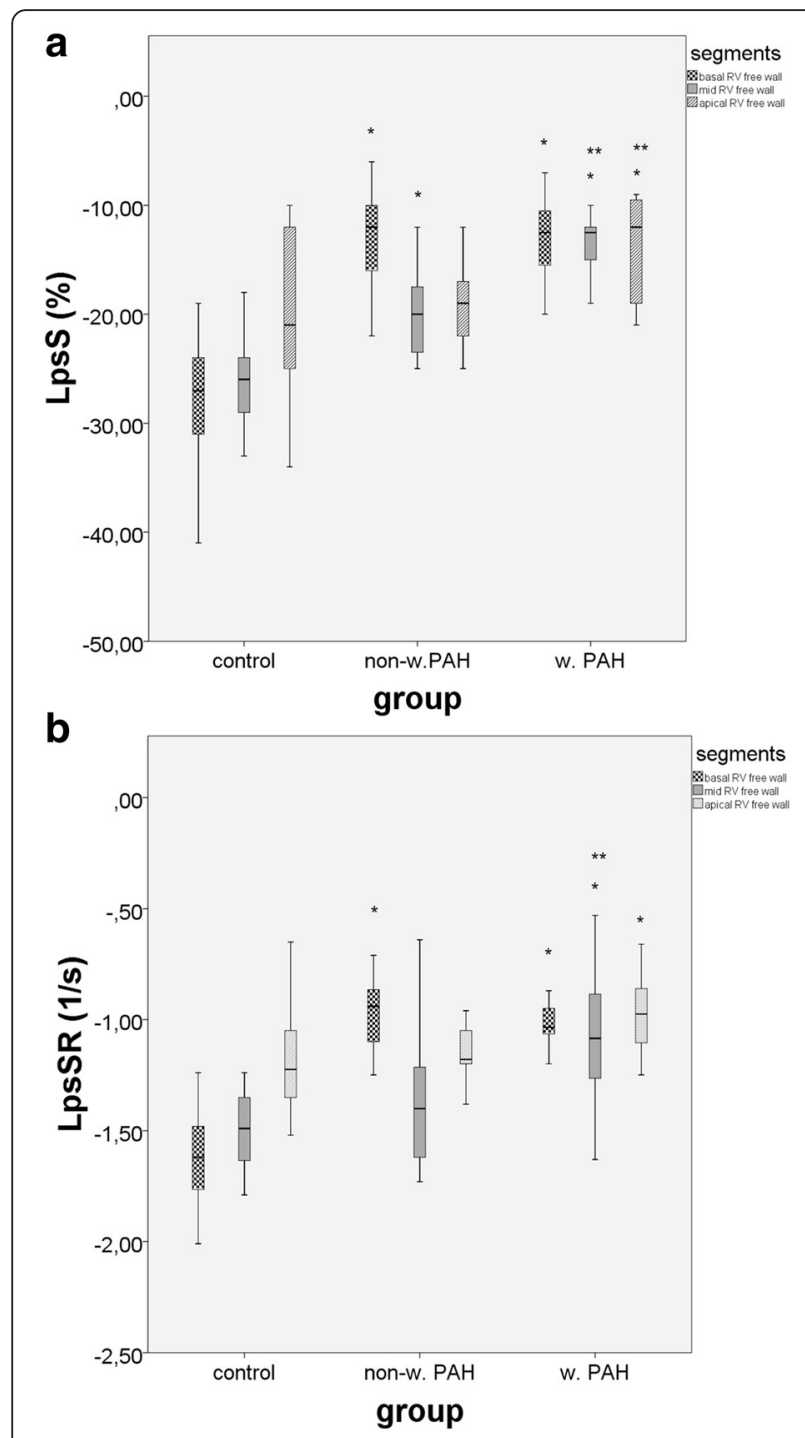

Fig. 4 Comparison between control group, non-worsening PAH patients and worsening PAH patients regarding $2 \mathrm{D}$ strain measurements of RV free wall segments: basal, mid and apical. a LpsS; b LpsSR. LpsS, longitudinal peak systolic strain;LpsSR, longitudinal peak systolic strain rate non-w, non-worsening; PAH pulmonary arterial hypertension; $\mathrm{RV}$, right ventricle; $w$, worsening; *non-w. or $w$. PAH vs control; ** W. vs non-w. PAH patients; $p<0.05$

Furthermore, our results show that RV free wall longitudinal strain indices (LpsS and LpsSR) are significantly lower in children with severe PAH compared with normal controls. However, it is important to underline that myocardial deformation is influenced by loading condition. Simon et al. revealed that, RV longitudinal strain can be decreased in both PAH patients with RV dysfunction and in PAH patients with preserved RV function. However, in the first situation RV strain was found to be much lower than in the second one [31, 32]. On the other hand, strain rate, representing the shortening velocity per fibre length, can describe more accurately the
Table 5 Multivariable logistic regression analysis for prediction of worsening in PAH patients

\begin{tabular}{lcll}
\hline Variable & Multivariate & & \\
\cline { 2 - 4 } & Odds ratio & $95 \% \mathrm{Cl}$ & $p$ \\
\hline BNP & 1.027 & $0.995-1.059$ & 0.097 \\
LV El & 0.082 & $0.000-49.076$ & 0.444 \\
Mid RV free wall LpsS & 0.458 & $0.217-0.967$ & 0.041 \\
Mid RV free wall LpsSR & 0.084 & $0.000-62.398$ & 0.462 \\
Apical RV free wall LpsS & 1.003 & $0.694-1.448$ & 0.989
\end{tabular}

$B N P$ brain natriuretic peptide, LpsS longitudinal peak systolic strain, $L p s S R$ longitudinal peak systolic strain rate, $L V$-El left ventricular eccentricity index, $P A H$ pulmonary arterial hypertension, $R V$ right ventricle

RV dysfunction. Ferferieva et al. demonstrated in an experimental study on mice, that strain rate correlates with the intrinsic contractile status of the myocardium, and is less influenced by changes in cardiac load [33]. Edvardson et al. revealed the clinical feasibility of strain rate imaging in quantifying regional systolic function [34].

\section{$\mathrm{RV}$ regional deformation pattern in children with PAH}

The RV has a complex anatomy, and can be divided in three distinct parts: smooth inlet portion, trabeculated apical portion and outlet portion. The RV free wall is composed by longitudinal fibers in the subendocardial layer, more developed in healthy subjects, and circumferential fibers in the superficial layer [35]. This explains why longitudinal shortening is the main component of RV pump function in healthy people [36].

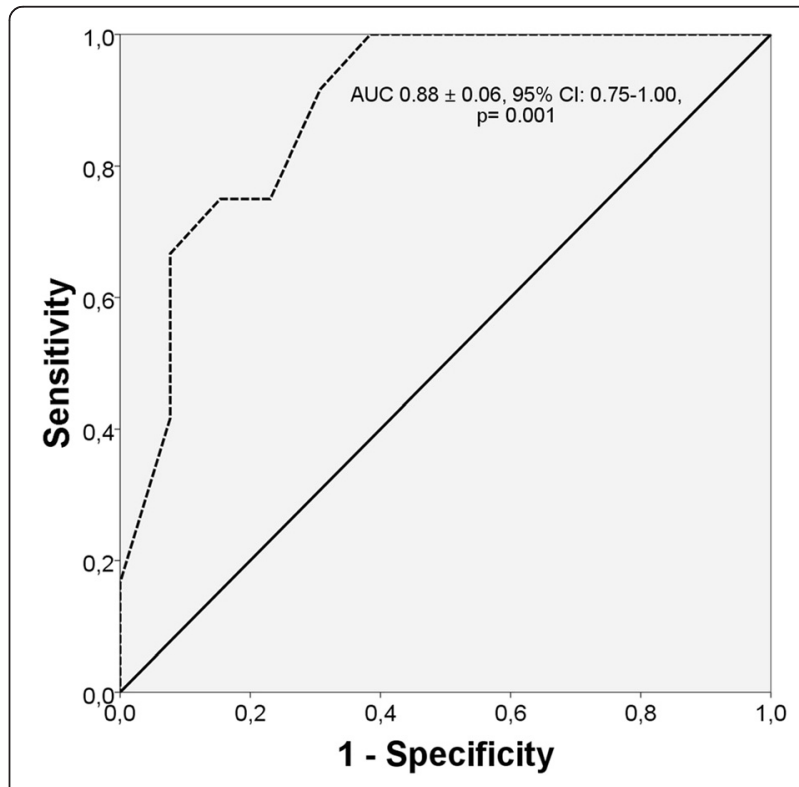

Fig. 5 Receiver-operator characteristic analysis. The optimum cutoff value for Mid RV free wall LpsS to predict clinical worsening was $-18.50 \%$; the sensitivity and specificity were 91.7 and $30.8 \%$. The area under curve was $0.88 \pm 0.06$ (95 \% Cl: $0.75-1.00, p=0.001$ ) 
We found a non-homogeneous decrease of the longitudinal strain indices in different segments of RV free wall in PAH patients, with loss of the base-to-apex gradient compared with normal controls. Consistent with the prior studies on pulmonary hypertension [29], our study showed impaired basal longitudinal strains in all $\mathrm{PAH}$ children. It has been demonstrated that the inlet portion is a greater contributor to right ventricular systolic function than the apical or outlet portion [37, 38]. We suppose that this could explain the greater decrease of strain and strain rate in PAH patients in the basal region of the RV free wall as compared with the mid or apical one.

Furthermore, we found a significant decrease of Mid and Apical RV free wall strain indices in worsening group as compared to non-worsening group. Mauritz et al. reported that in RV the longitudinal shortening reduction starts at the basal level and continue to decrease in other regions until a lower limit is reached. Also, they suggested that a further reduction of RV function is due to loss of transverse shortening with leftward septal displacement [39].

In conclusion, our findings suggest a deterioration pattern of regional longitudinal deformation of RV free wall myocardium in PAH children. There is an initial decrease of strain in the basal region; a further decrease in mid and apical region precedes clinical worsening in PAH children. However, these findings have to be validated in larger studies.

\section{Predictive value of $\mathrm{RV}$ regional deformation in children with PAH}

The predictive value of RV LpsS has been evaluated in adult patients with PAH. Haeck et al. demonstrated that RV global longitudinal strain $\geq-19 \%$ is associated with a 3-fold risk of all-cause mortality [40]. In a study conducted on 575 adult patients with $\mathrm{PAH}$, Fine et al. showed that RV free wall systolic strain predicted clinical outcome independent of other conventional echocardiographic parameters in adults [41]. Okumura et al. showed that RV global longitudinal $>-14 \%$, could predict transplantation-free survival in children with idiopathic pulmonary arterial hypertension [21].

However, the predictive value of RV regional deformation in PAH children was not studied so far. We found that Mid RV free wall strain indices are significantly lower in worsening group as compared to nonworsening group. Furthermore, we showed that Mid RV free wall LpsS is an independent predictor of worsening in PAH children and a cut-off value of $-18.50 \%$ is associated with clinical worsening in these patients. According to our study, Shehata et al. demonstrated by MRI, in a study conducted on PAH patients, that regional (basal and mid) longitudinal free wall deformation can already be affected at the time that RV function is still normal, implying that regional deformation could detect early RV dysfunction in PAH [42]. According to our knowledge this is the first study that describes the predictive value of RV regional deformation in children with PAH.

\section{Limits of the study}

The limitation of the study is that we did not compare our results with those obtained by magnetic resonance imaging (MRI), which is considered the "gold standard" method in RV function assessment. However, previous studies have validated the use of speckle-tracking derived strain against sonomicrometry [43] and magnetic resonance imaging [44]. An other limitation is the small number of the patients included in the present study. Further research with a larger number of children are needed to confirm these findings.

\section{Conclusion}

Two-dimensional speckle-tracking echocardiography is a complementary non-invasive tool for assessment of right ventricular function in children with severe pulmonary arterial hypertension, allowing clinical prediction and segmental analysis of right ventricular myocardial deformation in these patients.

\section{Abbreviations \\ 6MWD, 6-min walk distance; BNP, brain natriuretic peptide; chd, congenital heart defects; chd-PAH, pulmonary arterial hypertension associated with congenital heart defect; FAC, fractional area change; IVS, interventricular septum; LpsS, longitudinal peak systolic strain; LpsSR, longitudinal peak systolic strain rate; LV-EF, left ventricular ejection fraction; LV-El, left ventricular eccentricity index; MPI, myocardial performance index; $\mathrm{PAH}$, pulmonary arterial hypertension; PAPm, mean pulmonary arteial pressure; RA, right atrium; RV, right ventricle; S/D ratio, systolic/diastolic ratio; S', tricuspid annular systolic velocity; $\mathrm{SpO}_{2}$, oxygen saturation; SRV pressure, systolic right ventricular pressure; TAPSE, tricuspid annular plane systolic excursion; Tej, pulmonary ejection time; TR, tricuspid regurgitation; WHO, World Health Organization}

\section{Funding}

The present study was carried out in the research project no 27/11.12.2013, financed by local University of Medicine and Pharmacy Tîrgu-Mures, Romania.

\section{Authors' contributions}

IM: design, recruitment, image interpretation, data analysis, manuscript drafting. TB: recruitment, design, manuscript editing. MM: recruitment, data management. CS: recruitment, data management. RT: concept, data interpretation, critical revisions, final manuscript approval. All authors read and approved the final manuscript.

\section{Competing interests}

The authors declare that they have no competing interests.

\section{Ethics approval and consent to participate}

The study protocol was approved by the local Ethics Committee of the University of Medicine and Pharmacy of Tirgu Mures and written informed consent was given by parents or legal guardian.

\section{Author details}

${ }^{1}$ Clinic of Paediatric Cardiology, Institute of Cardiovascular Diseases and Transplantation, University of Medicine and Pharmacy, Tîrgu-Mures, Romania. ${ }^{2}$ Clinic of Cardiology, University of Medicine and Pharmacy, Tîrgu-Mures, Romania. ${ }^{3}$ Laboratory Department, Institute of Cardiovascular Diseases and 
Transplantation, Tîrgu-Mures, Romania. ${ }^{4}$ Clinic of Paediatric Cardiology, Institute of Cardiovascular Diseases and Transplantation, University of Medicine and Pharmacy Tîrgu-Mures, 50 Gh Marinescu St, Tîrgu-Mures 540136, Romania.

\section{Received: 5 May 2016 Accepted: 26 July 2016}

Published online: 29 July 2016

\section{References}

1. Ivy DD, Abman SH, Barst RJ, Berger RMF, Bonnet D, Fleming TR, Haworth SG, Raj JU, Rosenzweig EB, Neick IS, Steinhorn RH, Beghetti M. Pediatric pulmonary hypertension. JACC. 2013;62(25,SupplD):117-26.

2. Haworth SG, Hislop AA. Treatment and survival in children with pulmonary arterial hypertension: the UK Pulmonary Hypertension Service for Children 2001-2006. Heart. 2009:95:312-7.

3. Fraisse $A$, Jais $X$, Schleich JM, di Filippo S, Maragnes $P$, Beghetti $M$, Gressin V, Voisin M, Dauphin C, Clerson P, Godart F, Bonnet D. Characteristics and prospective 2-year follow-up of children with pulmonary arterial hypertension in France. Arch Cardiovasc Dis. 2010;103:66-74.

4. Barst RJ, McGoon MD, Elliott CG, Foreman AJ, Miller DP, Ivy DD. Survival in childhood pulmonary arterial hypertension: insights from the registry to evaluate early and long-term pulmonary arterial hypertension disease management. Circulation. 2012;125:113-22.

5. van Loon RL, Roofthooft MT, Hillege HL, ten Harkel AD, van Osch-Gevers M, Delhaas T, Kapusta L, Strengers JLM, Rammeloo L, Clur SAB, Mulder BJM, Berger RMF. Pediatric pulmonary hypertension in the Netherlands: epidemiology and characterization during the period 1991 to 2005. Circulation. 2011;124:1755-64

6. Van Loon RL, Roofthooft MT, Delhaas T, van Osch-Gevers M, ten Harkel AD, Strengers JLM, Backx A, Hillege HL, Berger RM. Outcome of pediatric patients with pulmonary arterial hypertension in the era of new medical therapies. Am J Cardiol. 2010;106:117-24.

7. Bernus A, Wagner BD, Accurso F, Doran A, Kaess H, Ivy DD. Brain natriuretic peptide levels in managing pediatric patients with pulmonary arterial hypertension. Chest. 2009;135:745-51.

8. Lammers AE, Hislop AA, Haworth SG. Prognostic value of B-type natriuretic peptide in children with pulmonary hypertension. Int J Cardiol. 2009;135:21-6.

9. Ghio S, Klersy C, Magrini G, D'Armini AM, Scelsi L, Raineri C, Pasotti M, Serio A, Campana C, Vigano M. Prognostic relevance of the echocardiographic assessment of right ventricular function in patients with idiopathic pulmonary arterial hypertension. Int J Cardiol. 2010;140:272-8.

10. D'Alonzo GE, Barst RJ, Ayres SM, Bergofsky EH, Brundage BH, Detre KM, Fishman AP, Goldring RM, Groves BM, Kernis JT, Levy PS, Pietra GG, Reid LM, Reeves JT, Rich S, Vreim CE, Williams GW, Wu M. Survival in patients with primary pulmonary hypertension. Results from a national prospective registry. Ann Intern Med. 1991;115:343-9.

11. Kassem E, Humpl T, Friedberg MK. Prognostic significance of 2-dimensional, $\mathrm{M}$-mode and Doppler echo indices of right ventricular function in children with pulmonary arterial hypertension. Am Heart J. 2013;165:1024-31.

12. Tei C. New non-invasive index for combined systolic and diastolic ventricular function. J Cardiol. 1995;26(2):135-6.

13. Lopez L, Colan SD, Frommelt PC, Ensing GJ, Kendall K, Younoszai AK, Lai WW, Geva T. Recommendations for quantification methods during the performance of a pediatric echocardiogram: a report from the Pediatric Measurements Writing Group of the American Society of Echocardiography Pediatric and Congenital Heart Disease Council. J Am Soc Echocardiogr. 2010;23:465-95.

14. Koestenberger M, Friedberg MK, Ravekes W, Nestaas E, Hansmann G. Noninvasive imaging for congenital heart disease: innovations in transthoracic echocardiography. J Clin Exp Cardiolog. 2012;Suppl 8:002.

15. Koestenberger M, Ravekes W, Everett A, Stueger HP, Heinzl B, Gamillscheg A, Cvirn G, Boysen A, Fandl A, Nagel B. Right ventricular function in infants, children and adolescents: reference values of the tricuspid annular plane systolic excursion (TAPSE) in 640 healthy patients and calculation of z-score values. J Am Soc Echocardiogr. 2009;22:715-9.

16. Koestenberger M, Nagel B, Ravekes W, Avian A, Heinzl B, Cvirn G, Fritsch P, Fandl A, Rehak T, Gamillscheq A. Reference values of the tricuspid annular peak systolic velocity in healthy pediatric patients, calculation of z-score values, and comparison to the tricuspid annular plane systolic excursion. Am J Cardiol. 2011;109:116-21.
17. Mertens L, Friedberg MK. Imaging of the right ventricle - current state of the art. Nat Rev Cardiol. 2010;7:551-63.

18. Teske AJ, De Boeck BWL, Melman PG, Sieswerda GT, Doevendans PA, Cramer MJM. Echocardiographic quantification of myocardial function using tissue deformation imaging, a guide to image acquisition and analysis using tissue Doppler and speckle tracking. Cardiovasc Ultrasound. 2007;5:27.

19. Meris A, Faletra F, Conca C, Klersy C, Regoli F, Klimusina J, Penco M, Pasotti E, Pedrazzini GB, Moccetti T, Auricchio A. Timing and magnitude of regional ventricular function: a speckle tracking -derived strain study of normal subjects and patients with right ventricular dysfunction. J Am Soc Echocardiogr. 2010;23(8):823-31.

20. Dragulescu A, Mertens LL. Developments in echocardiographic techniques for the evaluation of ventricular function in children. Arch Cardiovasc Dis. 2010;103:603-14.

21. Okumura K, Humpl T, Dragulescu A, Mertens L, Friedberg MK. Longitudinal assessment of right ventricular myocardial strain in relation to transplantfree survival in children with idiopathic pulmonary hypertension. J Am Soc Echocardiogr. 2014;27(12):1344-51.

22. Rudski LG, Lai WW, Afilalo J, Hua L, Handschumacher MD, Chandrasekaran K, Solomon SD, Louie EK, Schiller NB. Guidelines for the echocardiographic assessment of the right heart in adults: a report from the American Society of Echocardiography endorsed by the European Association of Echocardiography, a registered branch of the European Society of Cardiology, and the Canadian Society of Echocardiography. J Am Soc Echocardiogr. 2010;23:685-713.

23. Roberson DA, Cui W. Right ventricular Tei index in children: effect of method, age, body surface area, and heart rate. J Am Soc Echocardiogr. 2007;20:764-70.

24. Friedberg $\mathrm{MK}$, Silverman $\mathrm{NH}$. The systolic to diastolic duration ratio in children with hypoplastic left heart syndrome: a novel Doppler index of right ventricular function. J Am Soc Echocardiogr. 2007;20(6):749-55.

25. Crapo RO, Casaburi R, Coates AL, Enright PL, Maclntyre NR, McKay RT, Johnson D, Wanger JS, Zeballos RJ. ATS statement: guidelines for the sixminute walk test. Am J Respir Crit Care Med. 2002;166:111-9.

26. Rich $\mathrm{S}$, editor. Executive summary from the World Symposium on primary pulmonary hypertension. France: Evian; 1998.

27. Fukuda $Y$, Tanaka $H$, Sugiyama D, Ryo $K$, Onishi T, Fukuya $H$, Nogami $M$, Ohno Y, Emoto N, Kawai H, Hirata K. Utility of right ventricular free wall speckle-tracking strain for evaluation of right ventricular performance in patients with pulmonary hypertension. JASE. 2011;24(10):1101-8.

28. Dragulescu A, Grosse-Wortmann L, Redington A, Friedberg MK, Mertens L. Differential effect of right ventricular dilatation on myocardial deformation in patients with atrial septal defects and patients after tetralogy of Fallot repair. Int J Cardiol. 2012;168:803-10.

29. Levy PT, Mejia AAS, Machefsky A, Fowler S, Holland MR, Singh GK. Normal ranges of right ventricular systolic and diastolic strain measures in children: a systematic review and meta-analysis. JASE. 2014;27(5):549-60. e3.

30. Negishi K, Lucas S, Negishi T, Hamilton J, Marwick TH. What is the primary source of discordance in strain measurement between vendors: imaging or analysis? Ultrasound Med Biol. 2013;39:714-20.

31. Simon MA, Rajagopalan N, Mathier MA, Shroff SG, Pinsky MR, LópezCandales A. Tissue Doppler imaging of right ventricular decompensation in pulmonary hypertension. Congest Heart Fail. 2009;15:271-6.

32. Peluso D, Tona F, Muraru D, Romeo G, Cucchini U, Marra MP, lliceto S, Badano LP. Review right ventricular geometry and function in pulmonary hypertension: non-invasive evaluation. Diseases. 2014;2:274-95. doi:10.3390/diseases2030274.

33. Ferferieva $V$, Van den Bergh $A$, Claus $P$, Jasaityte $R$, Veulemans $P$, Pellens $M$, La Gerche A, Rademakers F, Herijgers P, D'hooge J. The relative value of strain and strain rate for intrinsic myocardial function. Am J Physiol Heart Circ Physiol. 2012;302(1):H188-95. doi:10.1152/ajpheart.00429.2011.

34. Edvardsen T, Skulstad H, Aakhus S, Urheim S, Ihlen H. Regional myocardial systolic function during acute myocardial ischemia assessed by strain Doppler echocardiography. J Am Coll Cardiol. 2001;37(3):726-30.

35. Ho SH, Nihoyannopoulos P. Anatomy, echocardiography and normal right ventricular dimensions. Heart. 2006:92(Suppl1):i2-13.

36. Rushmer RF, Crystal DK, Wagner C. The functional anatomy of ventricular contraction. Circ Res. 1953;1:162-70.

37. Vitarelli A, Conde Y, Cimino E, Stellato S, D'Orazio S, D'Angeli I, Nguyen BL, Padella V, Caranci F, Petroianni A, D'Antoni L, Terzano C. Assessment of right ventricular function by strain imaging in chronic obstructive pulmonary disease. Eur Respir J. 2006;27:268-75. 
38. Brili S, Stamatopoulos I, Misailidou M, Chrysohoou C, Tousoulis D, Tatsis I, Stefanidis C. Longitudinal strain curves in the RV free wall differ in morphology in patients with pulmonary arterial hypertension compared with controls. Int J Cardiol. 2013;167:2753-6.

39. Mauritz GJ, Kind T, Marcus JT, Bogaard HJ, van de Veerdonk M, Postmus PE, Boonstra A, Westerhof N, Vonk-Noordegraaf A. Progressive changes in right ventricular geomaetric shortening and long-term survival in pulmonary arterial hypertension. Chest. 2012;141:935-43.

40. Haeck MLA, Scherptong RWC, Marsan NA, Holman ER, Schalij MJ, Bax JJ, Vliegen HW, Delgado V. Prognostic value of right ventricular longitudinal peak systolic strain in patients with pulmonary hypertension. Circ Cardiovasc Imaging. 2012;5:628-36.

41. Fine NM, Chen L, Bastiansen PM, Frantz RP, Pellikka PA, Oh JK, Kane GC Outcome prediction by quantitative right ventricular function assessment in 575 subjects evaluated for pulmonary hypertension. Circ Cardiovasc Imaging. 2013;6(5):711-21.

42. Shehata ML, Harouni AA, Skrok J, Basha TA, Boyce D, Lechtzin N, Mathai SC, Girgis R, Osman NF, Lima JAC, Bluemke DA, Hassoun PM, Vogel-Claussen J. Regional and global biventricular function in pulmonary arterial hypertension: a cardiac MR imaging study. Radiology. 2013;266:1. http:// pubs.rsna.org/doi/abs/10.1148/radiol.12111599.

43. Korinek J, Wang J, Sengupta PP, Miyazaki C, Kjaergaard J, McMahon E, Abraham TP, Belohlavek M. Two-dimensional strain-a Doppler-independent ultrasound method for quantitation of regional deformation: validation in vitro and in vivo. J Am Soc Echocardiogr. 2005;18:1247-53.

44. Amundsen $B H$, Helle-Valle $T$, Edvardsen $T$, Torp $H_{\text {, Crosby J, Lyseggen } E}$ Stoylen A, Ihlen H, Lima JA, Smiseth OA, Slordahl SA. Noninvasive myocardial strain measurement by speckle tracking echocardiography: validation against sonomicrometry and tagged magnetic resonance imaging. J Am Coll Cardiol. 2006;47:789-93.

\section{Submit your next manuscript to BioMed Central and we will help you at every step:}

- We accept pre-submission inquiries

- Our selector tool helps you to find the most relevant journal

- We provide round the clock customer support

- Convenient online submission

- Thorough peer review

- Inclusion in PubMed and all major indexing services

- Maximum visibility for your research

Submit your manuscript at www.biomedcentral.com/submit 